\section{Modified percutaneous assisted transprosthetic endoscopic therapy for transgastric ERCP in a gastric bypass patient}

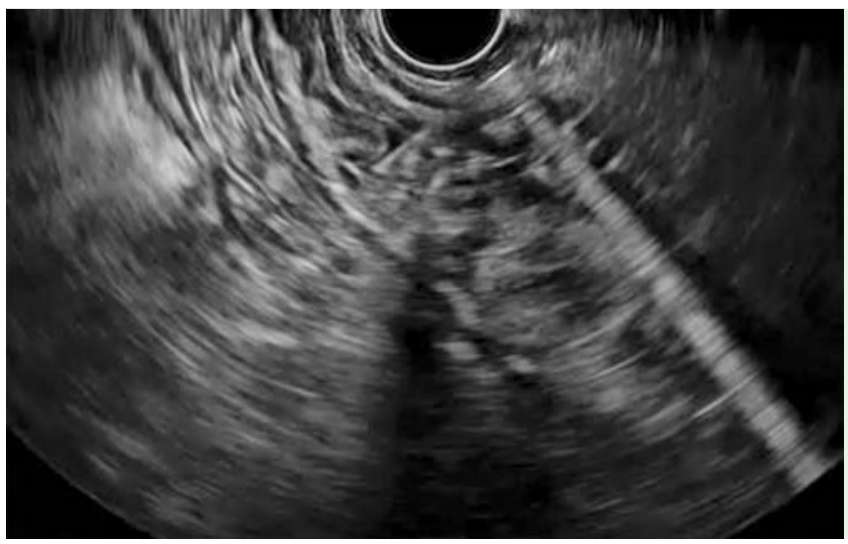

Fig. 1 Endoscopic ultrasound (EUS) image showing the puncture of the excluded stomach using a 19G fine needle aspiration (FNA) needle.

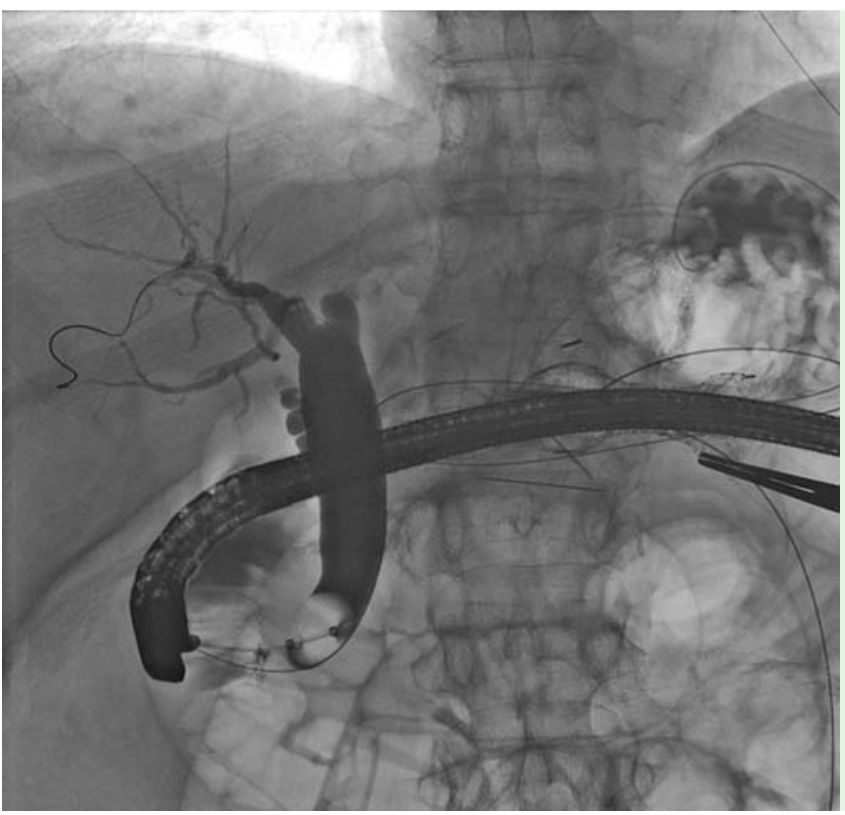

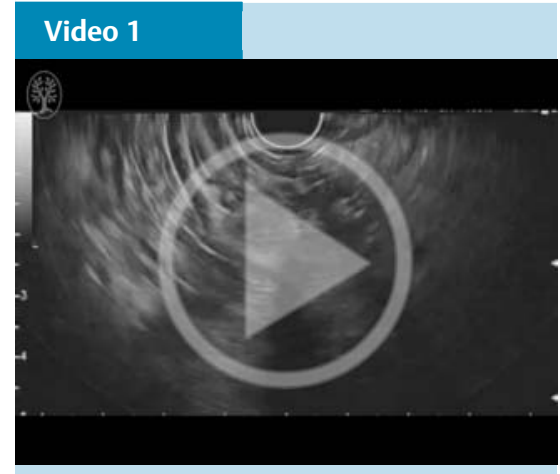

Transgastric endoscopic retrograde cholangiopancreatography (ERCP) being performed in a patient with a Roux-en-Y gastric bypass by combining the percutaneous assisted transprosthetic endoscopic therapy (PATENT) and endoscopic ultrasound-guided sutured gastropexy for transgastric ERCP (ESTER) techniques.

was passed into the excluded stomach and subsequently into the duodenum. The percutaneous access needle was removed leaving the guidewire in place. Three $\mathrm{T}$-fasteners were secured around the guidewire. Graduated dilation of the gastrostomy tract up to $18 \mathrm{Fr}$ was performed. A fully covered esophageal selfexpandable metal stent (SEMS; $20 \mathrm{~mm} \times$ $6 \mathrm{~cm}$ ) was deployed within the gastrostomy tract. The SEMS was dilated to $18 \mathrm{~mm}$ using a high burst pressure balloon dilator. A standard therapeutic duodenoscope was then passed through the SEMS. The bile duct was selectively accessed and cholangiography was performed ( Fig.2). Sphincterotomy was followed by sludge removal with an extraction balloon. Following ERCP, a 20-Fr replacement gastrostomy tube was placed. The SEMS was sectioned and removed.

No adverse events occurred. The total procedure time was 80 minutes. The patient was pain-free and was discharged home 2 days later. Repeat laboratory tests 4 days later revealed AST $62 \mathrm{IU} / \mathrm{L}$, ALT $146 \mathrm{IU} / \mathrm{L}$, total bilirubin of $1.2 \mathrm{mg} / \mathrm{dL}$, and alkaline phosphatase $304 \mathrm{IU} / \mathrm{L}$. Removal of the gastrostomy tube was planned for at least 6 weeks after the procedure.

Endoscopy_UCTN_Code_TTT_1AR_2AH 
Competing interests: Todd H. Baron: W.L. Gore, Boston Scientific, Olympus, and Cook Endoscopy.

\section{Ryan Law', Ian S. Grimm², Todd H. Baron²}

${ }^{1}$ Division of Gastroenterology, University of Michigan, Ann Arbor, Michigan, USA

${ }^{2}$ Division of Gastroenterology and Hepatology, University of North Carolina, Chapel Hill, North Carolina, USA

\section{References}

1 Law R, Wong Kee Song LM, Petersen BT et al. Single-session ERCP in patients with previous Roux-en-Y gastric bypass using percutaneous-assisted transprosthetic endoscopic therapy: a case series. Endoscopy 2013; 45: 671-675

2 Attam R, Leslie D, Arain MA et al. EUS-guided sutured gastropexy for transgastric ERCP (ESTER) in patients with Roux-en-Y gastric bypass: a novel, single-session, minimally invasive approach. Endoscopy 2015; 47: 646-649
Bibliography

DoI http://dx.doi.org/

10.1055/s-0041-110593

Endoscopy 2016; 48: E16-E17

(C) Georg Thieme Verlag KG

Stuttgart · New York

ISSN 0013-726X

Corresponding author

Todd H. Baron, MD

41041 Bioinformatics Blvd

CB 7080

Chapel Hill

NC 27599-0001

USA

Fax: +1-919-843-2508

todd_baron@med.unc.edu 